\title{
The Intrarenal Vascular Lesions in Renovascular Hypertension with Special Reference to Results of Surgical Treatment
}

\author{
Hideo Ueda, M.D., Takao Ikeda, M.D., Tadanao Takeda, M.D., \\ Eiichi Uchida, M.D., and Masao IsHII, M.D.
}

In order to detcrmine the relationship between results of surgery in renovascular hypertension and intrarenal vascular lesions, 10 hypertensive patients with uni- or bilateral main renal arterial stenosis were investigated. All of these patients were subjected to bilateral renal biopsy and were treated by surgical operation.

In 2 patients with slight intrarenal arterial sclerosis, normal blood pressure was achieved after operation. Even in 3 patients with moderate to severe intrarenal arterial and arteriolar sclerotic lesion, their diastolic blood pressure after operation was brought to below $90 \mathrm{~mm} . \mathrm{Hg}$, although one of them was administered small doses of an antihypertensive drug and the other 2 patients maintained slight systolic hypertension.

It appears from these results that in patients of renovascular hypertension with even severe intrarenal vascular lesions, revascularization of the stenotic renal artery may be beneficial for the future course of their hypertensive disease.

$I^{\mathrm{T}}$ has been considered by several investigators ${ }^{1-4)}$ that if patients with renovascular hypertension showed intrarenal vascular lesions reconstructive procedure was inadequate for the treatment of their hypertensive disease, and that preoperative biopsies of bilateral kidneys were required before correct selection of patients who should be sent for surgery was made. Recently, however, Strickler ${ }^{5}$ reported a case who had severe intrarenal involvement associated with malignant hypertension caused by bilateral main renal artery stenosis and was cured by surgical reconstruction of stenotic renal arteries.

The present study concerns the significance of intrarenal vascular lesions to results of surgical vascular repair in renovascular hypertension on 10 patients who underwent bilateral renal biopsies.

\section{Materials and Methods}

Ten patients with stenosis of one or both main renal arteries were investigated. The patients ranged in age from 19 to 48 years old and consisted of 4 males and 6

From the Second Department of Internal Medicine, Faculty of Medicine, University of Tokyo, Tokyo.

Received for publication January 30, 1966. 


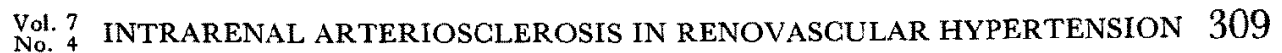

Case 1 T.U.

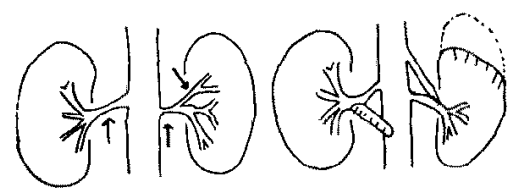

L. Splenorenal shunt +partial nephrectomy

R. Tefion bypass grafting

Case 2 R.E.

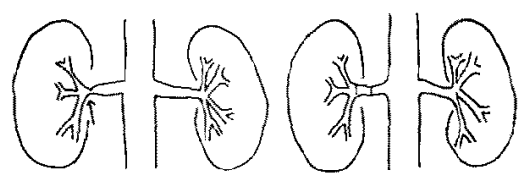

R. Autologous saphenous vein patch grafting

Case 3 E.T.

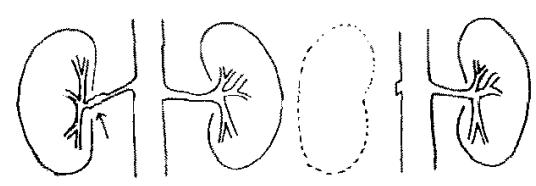

R. Nephrectomy

Case 4 A.K.

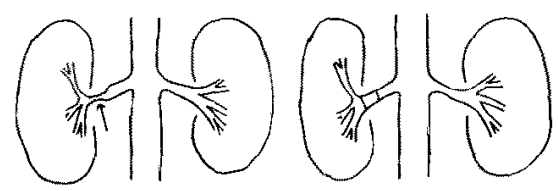

R. Autologous saphenous vein patch grafting

Case 5 H.I.
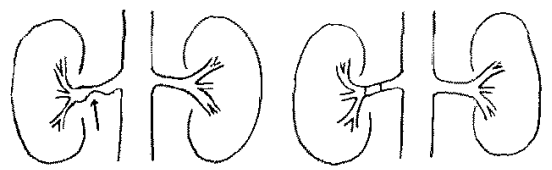

R. Autologouos saphenous vein patch grafting
Case 6 T.W.

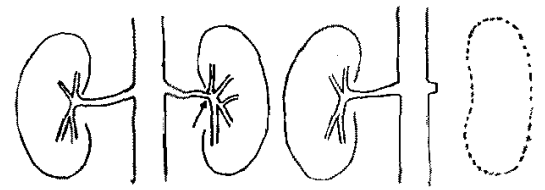

L. Nephrectomy

Case 7 K.A.

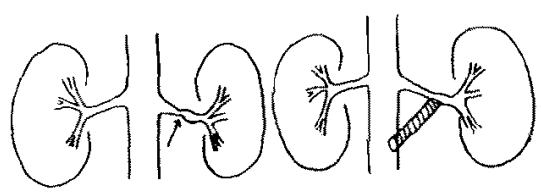

L. Teflon bypass grafting

Case 8 S.U.
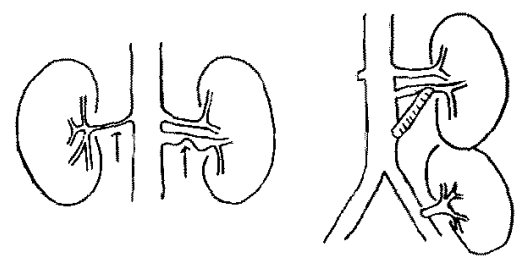

L. Teflon bypass grafting

tautotransplantation of right kidney in left common iliac artery

Case 9 M.T.

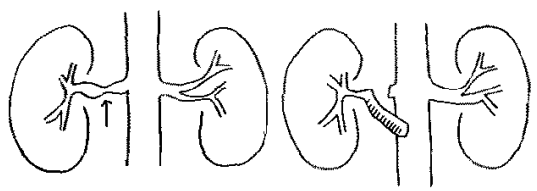

R. Teflon bypass grafting Case 10 R.S.

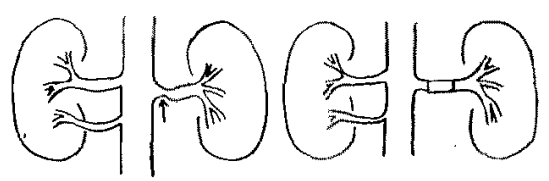

R. Teflon patch grafting

Fig. 1. Schema of aorticorenal arteriographic finding and operative procedure 
females. All of these patients were admitted to the Second Department of Internal Medicine of Tokyo University Hospital and subsequently were operated upon with vascular reconstruction or uninephrectomy in the Second Department of Surgery of the same hospital in attempts to reduce their elevated blood pressure.

Bilateral renal biopsies, renal arteriography and split renal function test were performed in all patients. Renal biopsy specimens were obtained percutaneously using a modification of Vim-Silverman needle or by wedge biopsy at operation. The tissue obtained by these procedures was fixed immediately in formalin and stained with usual stains. Percutaneous transfemoral, retrograde aorticorenal arteriography was carried out by the technic of Seldinger. ${ }^{6)}$ Split renal function test was performed according to Howard."

The post-operative follow-up of blood pressure was performed in 8 patients at least for 14 months. In these patients their blood pressure was measured in sitting position at our outpatient clinic. In 2 patients post-operative blood pressure was recorded for 1 month after operation in the hospital.

\section{Results}

The patients were divided into 3 groups according to intrarenal sclerotic findings of renal biopsy specimen. Group I consisted of 5 patients without any evidence of intrarenal sclerotic changes, Group II, 2 patients with slight intrarenal sclerotic findings, and Group III, 3 patients with moderate to severe intrarenal sclerotic findings.

Table I. Clinical Data and

\begin{tabular}{c|c|c|c|c|c|c}
\hline Case No. & Patient & Age & Sex & $\begin{array}{c}\text { Duration of } \\
\text { Hypertension }\end{array}$ & $\begin{array}{c}\text { Blood Pressure } \\
\text { (mm. Hg) }\end{array}$ & $\begin{array}{c}\text { Retinal } \\
\text { Finding* }\end{array}$ \\
\hline Group I (No intrarenal sclerosis) \\
1 & T. U. & 20 & M & $3 \mathrm{~m}$ & $174 / 118$ & IV \\
2 & R. E. & 25 & F & $2 \mathrm{y}$ & $190 / 116$ & I \\
3 & E. T. & 19 & F & $6 \mathrm{~m}$ & $179 / 107$ & I \\
4 & A. K. & 27 & F & $2 \mathrm{y}$ & $220 / 118$ & II \\
5 & H. I. & 23 & F & $4 \mathrm{~m}$ & $210 / 126$ & I \\
\hline
\end{tabular}

Group II (Slight intrarenal sclerosis)

\begin{tabular}{l|l|l|l|l|l|l}
6 & T. W. & 20 & F & $2 \mathrm{y}$ & $220 / 121$ & I \\
7 & K. A. & 22 & F & $6 \mathrm{~m}$ & $205 / 115$ & I \\
\hline
\end{tabular}

Group III (Moderate to severe intrarenal sclerosis)

\begin{tabular}{r|l|l|l|l|l|l}
8 & S. U. & 38 & M & $2 \mathrm{y}$ & $280 / 140$ & I \\
9 & M. T. & 31 & M & $7 \mathrm{y}$ & $220 / 120$ & II \\
10 & R. S. & 55 & M & $6 \mathrm{~m}$ & $194 / 104$ & II
\end{tabular}

* Classification of Keith and Wagener

** Clearance of para-amino-hippurate

*** Clearance of endogenous creatinine 


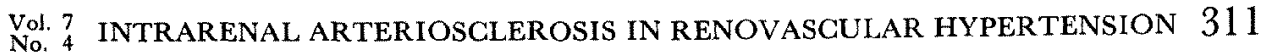

Sex, age, duration of hypertension, blood pressure, retinal finding, total renal plasma flow and glomerular filtration rate, albuminuria, and side and pathology of the stenotic artery of these patients were shown in Table I. All of these patients revealed marked elevation of diastolic blood pressure. Total renal function estimated by clearance of para-amino-hippurate and endogenous creatinine was found normal or only slightly decreased. Split renal function tests revealed positive results compatible with a stenotic side in unilateral renal artery stenosis and with more severely ischemic side in bilateral renal artery stenosis by Rapoport criteria ${ }^{8}$ in all patients. Pathology of the stenotic artery was fibromuscular hyperplasia in 5 cases, arteritis in 2 cases, arteriosclerosis in 2 and idiopathic thrombosis in 1 patient.

The aorticorenal arteriographic findings and methods of surgery in these patients were presented schematically in Fig. 1. Stenosis of both-side renal arteries was noted in 2 patients. Surgical revascularization was performed by patch grafting on the stenotic artery in 4 patients, and bypass teflon grafting between the aorta and the renal artery in 4 patients and unilateral nephrectomy was carried out in 2 patients. Beside one of these procedures, splenorenal anastomosis associated with ipsilateral partial nephrectomy was performed in 1 patient and autotransplantation of the right hypoperfused kidney to the left common iliac artery in one patient.

In all cases except one, vascular reconstruction recovered their renal

Pathology of Stenotic Artery

\begin{tabular}{|c|c|c|c|l}
\hline Albuminuria & $\begin{array}{c}\text { RPF** } \\
\text { (ml./min.) }\end{array}$ & $\begin{array}{c}\text { GFR*** } \\
\text { (ml./min.) }\end{array}$ & $\begin{array}{c}\text { Stenotic } \\
\text { Side }\end{array}$ & Pathology of Stenotic Artery \\
\hline \multirow{2}{*}{ trace } & 833 & 83 & Both & Arteritis \\
trace & 699 & 114 & Right & Fibromuscular Hyperplasia \\
trace & 418 & 78 & Right & Fibromuscular Hyperplasia \\
$(+)$ & 416 & 60 & Right & Idiopathic Thrombosis \\
$(-)$ & 381 & 54 & Right & Fibromuscular Hyperplasia \\
& & & & \\
trace & 691 & 72 & Left & Fibromuscular Hyperplasia \\
$(-)$ & & & Left & Arteritis \\
& & & & \\
$(-)$ & 404 & 77 & Both & Fibromuscular Hyperplasia \\
trace & 545 & 96 & Right & Arteriosclerosis \\
$(+)$ & 295 & 71 & Left & Arteriosclerosis and Thrombosis \\
\end{tabular}


circulation. In case $1, T$. U., operative procedures did not succeed to repair his renal ischemia completely probably due to incomplete partial nephrectomy.

Renal histopathologic findings: Intrarenal vascular abnormalities were not found in both kidneys of 5 patients (Case 1-5, Group I). Slight sclerotic changes of small arteries in the contralateral kidney to a stenotic side were noted in 2 patients (Case 6, 7, Group II). In case 8, one stenotic renal artery in the right side and 2 renal arteries, one of which was stenotic, in left side were noted. The right kidney, which was ischemic as a whole, showed slight thickening of wall of small arteries and arterioles including some obsolete glomeruli as well as focal round cell infiltration, and the right kidney revealed almost normal appearance in an area supplied by the stenotic artery, whereas moderate thickening of small arterial wall and hyaline sclerosis of arteriolar wall in the part supplied by the nonstenotic artery (Fig. $2 \mathrm{~A}, \mathrm{~B}$ ). In case 9, both the right kidney supplied by stenotic artery and the left supplied by the nonstenotic artery revealed moderate to severe intrarenal arterial and arteriolar sclerosis. Especially in the nonstenotic left kidney marked intimal thickening of small arteries and hyaline degeneration of arteriolar wall associated with

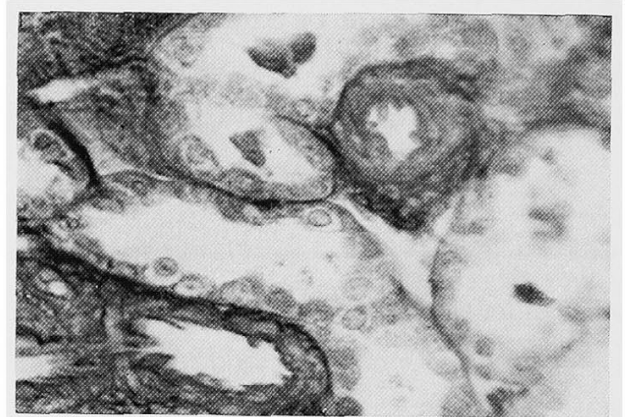

Fig. 2 A. Case 8 S. U. Right kidney. Slight thickening of arteriolar wall is noted. (Mallory Azan stain 1:400)
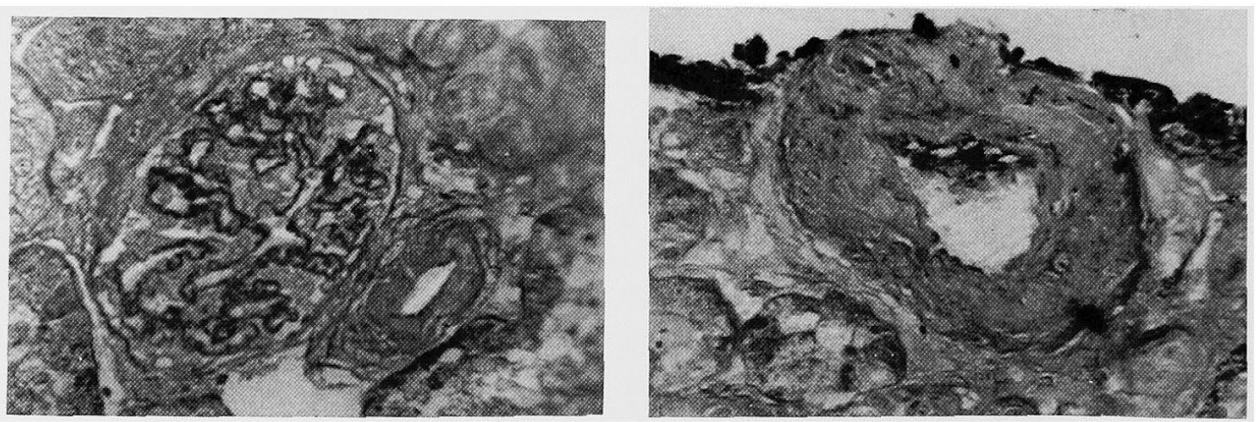

Fig, 2 B. Case 8 S. U. Left kidney supplied by non-stenotic renal artery. Moderate thickening of small arterial wall and hyaline sclerosis of arteriole are noted. (Mallory Azan stain 1:400) 
scattered obsolete glomeruli and focal stromal cell infiltration were remarkable (Fig. $3 \mathrm{~A}, \mathrm{~B}$ ). In case 10 marked thickening of small arterial wall was found in the stenotic left side (Fig. 4), on the other hand only slight sclerotic changes of small arteries was noted in specimens obtained from the contralateral kidney.

Follow-up Studies: Five patients of Group I and II (Case 2, 3, 4, 5, 6) whose intrarenal arteriosclerotic changes were absent or slight, their blood pressure remained normal range through more than 1 year after operation.

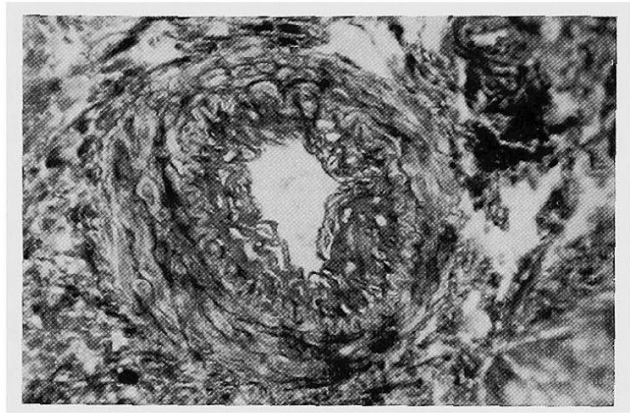

Fig. 3A. Case 9 M. T. Right kidney. Severe intimal thickening and medial hypertrophy of small artery are noted. (Mallory Azan stain 1:400)
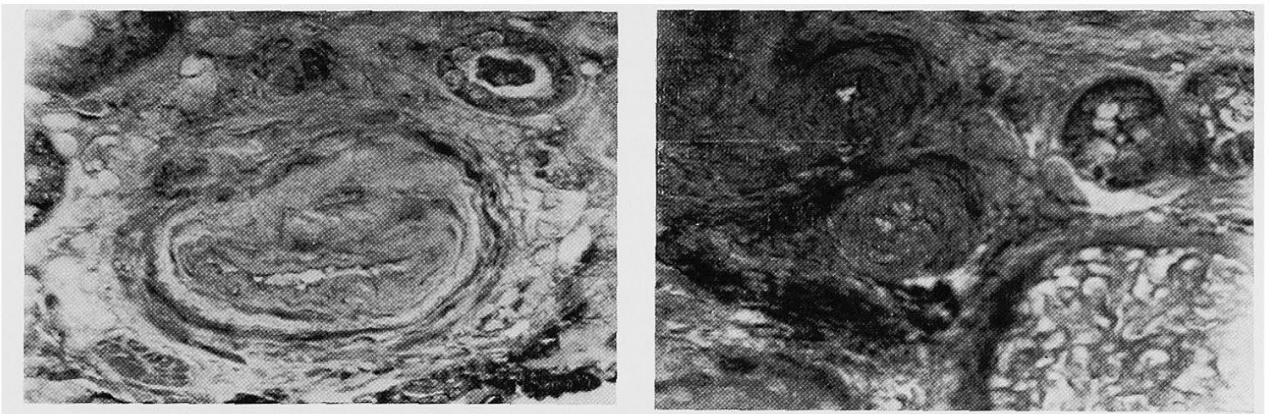

Fig. 3 B. Case 9 M. T. Left kidney. Marked intimal thickening with narrowing of lumen in small artery as well as arterioles are noted. (Mallory Azan stain $1: 400$ )

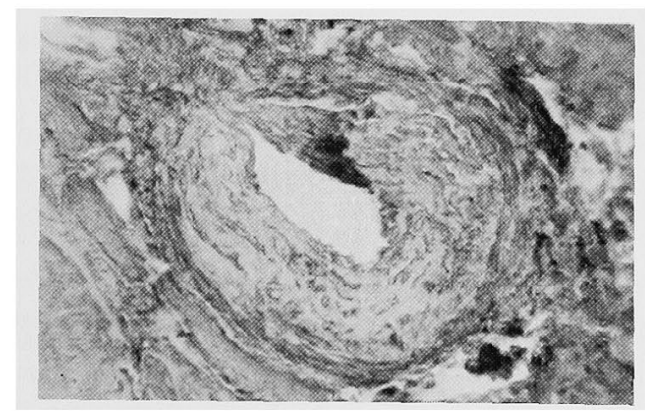

Fig. 4. Case 10 R. S. Left kidney. Marked thickening of small arterial wall is noted. (Mallory Azan stain 1:400) 
In one patient of Group II (Case 7) who showed slight intrarenal vascular sclerosis, blood pressure fell to a normal level soon after operation but observation period was only 22 days till her leaving hospital. One patient of Group I (Case 1) who did not show any intrarenal vascular lesion in both kidneys failed to have his blood pressure lowered probably due to inadequate partial nephrectomy. Three patients of Group III (Case 8,9,10) showed various follow-up blood pressure. Case 8, S. U. was operated in February 1964, and his blood pressure fell soon after operation to $146 / 90 \mathrm{~mm}$. $\mathrm{Hg}$ as compared with $280 / 140 \mathrm{~mm}$. $\mathrm{Hg}$ before surgery and he left our hospital. But in October 1964 when he first visited our outpatient clinic his blood pressure was $150 / 108 \mathrm{~mm}$. $\mathrm{Hg}$, then $0.8 \mathrm{mg}$. of reserpine was administered until January 1965 and blood pressure fell to a normal range. From January to August 1965 his blood pressure was maintained at 138-120/94-84 without any medical treatment. But by December 1965, his blood pressure was elevated to $144 / 104$ $\mathrm{mm}$. $\mathrm{Hg}$ again and immediately fell within normal blood pressure by administration of $0.5 \mathrm{mg}$. of reserpine. In case $9, \mathrm{M}$. T., surgical revascularization was

Table II. Blood Pressure before and after Operation and Operative Procedure

\begin{tabular}{|c|c|c|c|c|c|c|c|}
\hline \multirow[b]{2}{*}{$\begin{array}{l}\text { Case } \\
\text { No. }\end{array}$} & \multirow[b]{2}{*}{ Patient } & \multirow[b]{2}{*}{ Age } & \multirow[b]{2}{*}{ Sex } & \multicolumn{2}{|c|}{ Blood Pressure } & \multirow[b]{2}{*}{$\begin{array}{l}\text { Follow-up } \\
\text { Period }\end{array}$} & \multirow[b]{2}{*}{ Operative Procedure } \\
\hline & & & & $\begin{array}{c}\text { Before } \\
\text { Operation } \\
(\mathrm{mm} . \mathrm{Hg})\end{array}$ & $\begin{array}{c}\text { After } \\
\text { Operation } \\
(\mathrm{mm} . \mathrm{Hg})\end{array}$ & & \\
\hline \multicolumn{8}{|c|}{ Group I (No intrarenal sclerosis) } \\
\hline 1 & T.U. & 20 & M & $174 / 118$ & $190 / 118$ & ly $7 \mathrm{~m}$ & $\begin{array}{l}\text { Left splenorenal shunt }+ \text { Partial } \\
\text { nephrectomy }\end{array}$ \\
\hline 2 & R. E. & 25 & F & $190 / 116$ & $120 / 70$ & $2 y 7 \mathrm{~m}$ & $\begin{array}{l}\text { Right teflon bypass grafting } \\
\text { Right autologous saphenous vein } \\
\text { patch grafting }\end{array}$ \\
\hline 3 & E. T. & 19 & $\mathbf{F}$ & $179 / 107$ & $125 / 85$ & $2 y 1 \mathrm{~m}$ & Right nephrectomy \\
\hline 4 & A. $\mathrm{K}$. & 27 & $\mathbf{F}$ & $220 / 118$ & $128 / 88$ & $1 y 5 m$ & $\begin{array}{l}\text { Right autologous saphenous vein } \\
\text { patch grafting }\end{array}$ \\
\hline 5 & H. I. & 23 & $\mathrm{~F}$ & $210 / 126$ & $128 / 80$ & $1 y 4 m$ & $\begin{array}{l}\text { Right autologous saphenous vein } \\
\text { patch grafting }\end{array}$ \\
\hline
\end{tabular}

Group II (Slight intrarenal sclerosis)

\begin{tabular}{l|l|l|l|l|l|r|l}
6 & T. W. & 20 & F & $220 / 121$ & $126 / 80$ & ly $4 \mathrm{~m}$ & Left nephrectomy \\
7 & K. A. & 22 & F & $205 / 115$ & $132 / 84$ & $22 \mathrm{~d}$ & Left teflon bypass grafting
\end{tabular}

Group III (Moderate to severe intrarenal sclerosis)

\begin{tabular}{r|l|l|l|l|l|ll|l}
8 & S. U. & 38 & M & $280 / 140$ & $134 / 84$ & $1 y 3 \mathrm{~m}$ & $\begin{array}{c}\text { Left teflon patch grafting + Auto- } \\
\text { transplantation of right kidney } \\
\text { to left iliac artery } \\
\text { Right teflon bypass grafting }\end{array}$ \\
9 & M. T. & 31 & M & $220 / 120$ & $156 / 86$ & ly $5 \mathrm{~m}$ & $\begin{array}{l}\text { Righ } \\
\text { Right teflon patch grafting }\end{array}$
\end{tabular}


performed in April 1964, and soon after operation his blood pressure fell to $150 / 70 \mathrm{~mm}$. Hg as compared with $220 / 120 \mathrm{~mm}$. Hg of the preoperative level, and 17 months after operation his blood pressure was $156 / 86 \mathrm{~mm}$. $\mathrm{Hg}$ in our outpatient clinic. He was complicated with hyperthyroidism showing plus 40 per cent of basal metabolic rate in above mentioned follow-up period. Therefore his slightly elevated systolic blood pressure after surgery may have been caused by this complication. In case 10, R. S., surgical procedure was carried out in this February, and on the 30th day after surgery blood pressure was $154 / 86 \mathrm{~mm} . \mathrm{Hg}$ in recumbent position as compared with $194 / 104 \mathrm{~mm}$. Hg before operation. Postoperative follow-up blood pressure was shown in Table II.

\section{Discussion}

It has been observed that partial constriction of one renal artery in the rat will lead to sustained hypertension and the development of severe vascular changes in the opposite kidney identical with changes seen in malignant nephrosclerosis in man, ${ }^{2)}$ and similar observation was made in human renovascular hypertension by Bauer and Forbes. ${ }^{10}$ In the early stages of the above experiment the blood pressure may be restored to normal by removing the constriction, but after several months removal of the constriction results only in partial return to normal and complete return to normal blood pressure could be achieved by removal of constriction and contralateral nephrectomy. ${ }^{91}$ In 1963, Thal, Grage, and Vernier ${ }^{11)}$ demonstrated this fact in human renovascular hypertension. They reported a case of severe hypertension of at least 7 years duration due to coarctation of the right renal artery associated with advanced hypertensive pathology in the opposite kidney treated by surgical procedure. First, the patient was treated by reconstruction of the stenotic right renal artery and after 8 months' observation of persistent moderate hypertension, the left kidney which showed severe hypertensive changes consisted of severe intimal fibrous thickening and medial hyperplasia of the small arteries was removed with prompt return of blood pressure to normal levels.

Vertes, Granuel, and Goldblatt ${ }^{11}$ reported in 1965 that in 7 hypertensive patients with stenosis of a main renal artery but with an intrarenal cause of ischemia due to moderate to severe arteriolar sclerosis in both kidncys, correction of the stenosis did not result in a permanent improvement of the blood pressure. They emphasized that particular attention should be paid to the histologic structure of both kidneys before corrective surgery was undertaken, and patients with an intrarenal cause of renal ischemia should be excluded from surgical intervention. On the basis of a follow-up study of 23 patients 
treated by revascularization or uninephrectomy of the affected side, Baker, Page, and Leadbetter" showed that the degree of nephrosclerosis was greatest in patients who were unimproved after operation. They suggested that if nephrosclerosis was present in a frozen section of a renal biopsy the advisability of proceeding with vascular repair should be questioned. Thus it was considered by these investigators that if there were intrarenal arterial and arteriolar sclerotic changes causing renal ischemia in either stonotic or nonstenotic side surgical repair of stenotic proximal artery was inadequate. At least, contralateral uninephrectomy was needed after reconstruction of the stenotic artery for complete recovery to normal blood pressure level, if intrarenal vascular lesion was confined to the kidney of the non-stenotic side.

Recently, however, Strickler ${ }^{51}$ reported a surgically cured case of malignant hypertension secondary to bilateral renal artery obstruction associated with documented renal parenchymal small vessel disease. His contention is that surgical revascularization may help hypertensive patients who have intrarenal vascular disease and main renal artery obstruction if all criteria of the classical Howard test are met and withholding renovascular surgery on the sole basis of renal biopsy demonstration of small vessel disease is inadvisable.

The present study shows that the adequate surgical operation lowered the elevated blood pressure to normal in patients with slight intrarenal vascular sclerosis as in patients without histologic abnormalities of intrarenal vessels. Even in patients with moderate to severe intrarenal vascular lesions, the diastolic blood pressure fell below $90 \mathrm{~mm}$. $\mathrm{Hg}$ after reconstruction of the stenotic renal artery, although in a patient sometimes small doses of an antihypertensive drug was administered and the other 2 patients showed slight systolic hypertension.

Our present data suggest that even if severe intrarenal vascular changes be found in either kidney of patients with renovascular hypertension, adequate surgical revascularization may lead their blood pressure to lower levels sufficient to need little or no medical therapy. It is our contention, therefore, that in such cases surgical intervention for repair of the stenotic renal artery should be undertaken for the benefit of the future course of their hypertensive disease.

Pathogenesis of severe intrarenal arterial sclerotic lesions seen in the hypoperfused kidney of case 9 and 10 was obscure. One possible explanation is that these intrarenal vascular lesions might be of the same pathogenesis as the stenotic lesion of the main renal artery.

Further observations will be required to establish exact indications for vascular surgery in hypertensive patients with renal artery stenosis and intrarenal lesions. For this purpose, it seems necessary to perform bilateral renal biopsies prior to surgery, which will provide much more informations on in- 


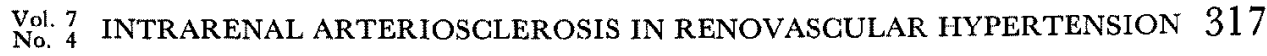
trarenal pathology for the prospective view of the outcome of surgery.

\section{Summary}

Ten hypertensive patients due to renal arterial stenosis were studied to determine the relationship between results of surgical revascularization and bilateral renal biopsy findings.

Seven patients including 5 with no intrarenal vascular lesion and 2 with slight arteriosclerosis, normal blood pressure was achieved after operation except in a case in whom surgery failed to repair his renal ischemia.

In 3 patients showing moderate to scverc intrarenal small vessel discase, diastolic blood pressure was lowered to below $90 \mathrm{~mm}$. $\mathrm{Hg}$, although one of them needed sometimes small doses of a hypotensive drug postoperatively.

On the basis of the present results, it is postulated that patients of renovascular hypertension even with intrarenal vascular changes, should be treated by surgical reconstruction of the stenotic renal artery whenever the procedure is adequately feasible.

\section{AGKNowledgement}

The authors wish to express their thanks to Prof. S. Kimoto, Dr. A. Ueno and their co-workers who conducted the operations.

\section{References}

1. Vertes, V., Granuel, J. A., and Goldblatt, H.: New. Engl. J. Med. 272 : 186, 1965.

2. Vertes, V., Granuel, J. A., and Goldblatt, H. : New. Engl. J. Med. 270 : 656, 1964.

3. Vertes, V. and Granuel, J.A.: Girculation 28 : 536, 1963.

4. Baker, G. P., Page, L. B., and Leadbetter, G. W. : New. Engl. J. Med. 267; 1325, 1962.

5. Strickler, W. L.: J. A. M. A. $194: 233,1965$.

6. Seldinger, S. L. : Acta Radiol. $39: 368,1953$.

7. Connor, T. B., Thomas, W. C., Haddock, L., and Howard, J. E. : Ann. Int. Med. 52 : 544 , 1960.

8. Rapoport, A.: New Engl. J. Med. 263: 1159, 1960.

9. Floyer, M. A.: Clin. Sc. 19: 405, 1951.

10. Bauer, H. and Forbes, I.: Am. Heart J. 44: 634, 1952.

11. Thal, A. P., Grage, T. B., and Vernier, R. I.: Circulation $27: 36,1963$. 